Exposed children scored 5 points lower on the Chinese versions of the Stanford-Binet and WISC-R at ages $4-5$ and $6-7$ years, respectively. Children born up to 6 years after maternal exposure and tested at 6 and 7 years of age were as affected as those born within a year after exposure. (Chen Y-CJ, Rogan WJ et al. Cognitive development of Yu-Cheng ("oil disease") children prenatally exposed to heat-degraded PCBs. IAMA Dec 9 1993; 268: 3213-3218). (Reprints: Dr Chen, Department of Psychiatry, National Cheng Kung University Medical College, 138 Sheng Li Rd, Tainan 70428, Taiwan, Republic of China).

COMMENT. In the US children born to women who routinely consumed Lake Michigan sportfish had poorer short-term memory function on both verbal and quantitative tests in a dose-dependent fashion (Jacobson JL et al. Effects of in utero exposure to polychlorinated biphenyls and related contaminants on cognitive functioning in young children LPediatr 1990; 116: 38). Rogan WJ, an author of the Taiwan report, has written several articles on the in utero effects of PCBs on child development, a hazard that requires effective governmental disposal. (Also see Environmental Poisons in our Food, Millichap JG, Chicago, PNB Publ, 1993, 271 pp).

\title{
LEAD EXPOSURE AND MOTOR DEVELOPMENT
}

The neuromotor assessment of 245 six-year-old urban inner-city children enrolled in the Cincinnati Lead Study is reported from the Departments of Environmental Health and Pediatrics, University of Cincinnati College of Medicine, and the Children's Hospital Medical Center, Cincinnati, OH. Quarterly measures of blood lead and development since birth showed that neonatal, but not prenatal blood lead levels were associated with impaired coordination, hand speed and dexterity. Postnatal blood lead levels were associated with similar impairments of coordination, and poorer scores on visual-motor control. Low to moderate lead exposure is associated with moderate deficits in gross and especially fine-motor development. Blood lead levels peaked at 2 years of age and then slowly declined; 87 children (35\%) had levels of $25 \mathrm{mcg} / \mathrm{dL}$ or greater during the first 5 years of life, while 195 (80\%) had at least one level at or above $15 \mathrm{mcg} / \mathrm{dL}$ during this period. Only $5 \%$ were chelated therapeutically. (Dietrich KN, Berger OG, Succop PA. Lead exposure and the motor developmental status of urban six-year-old children in the Cincinnati prospective study. Pediatrics Feb 1993; 91: 301-307). (Reprints: Dr Dietrich, University of Cincinnati College of Medicine, Dept of Environmental Health, Cincinnati, OH 45267).

COMMENT. The cerebellum is particularly sensitive to lead intoxication in neonatal rats, and glial cell development and brain histogenesis are affected. In children of low socioeconomic status, motor development 
and coordination may be more sensitive indicators of the adverse effects of lead on the central nervous system than tests of intelligence and academic achievement. Lead poisoning is now defined as a blood lead level greater than or equal to $10 \mathrm{mcg} / \mathrm{dL}$. Children aged 6 months to 6 years and those living in older housing are the highest priority for screening, mandatory in many States.

\section{INTRACRANIAL TUMORS}

\section{MENINGIOMAS: MRI AND PATHOLOGICAL FINDINGS}

MRIs and histopathological studies of five children, aged 3 months to 16 years, with extra-axial meningiomas are reported from the Arkansas Children's Hospital and University of Arkansas for Medical Sciences, Little Rock, AR. Two tumors were supratentorial and three were in the posterior fossa. Two located on the tentorium presented with headache, and one at the foramen magnum caused quadriparesis. All were hyperintense on proton density- and T2-weighted images and showed intense contrast enhancement on T1-weighted images. Two were meningotheliomatous, one transitional, one chordoid, and one hemangiopericytic variant of meningioma. Chromosome 22 deletions were found in two of four tumors studied. (Glasier CM et al. Meningiomas in children: MR and histopathologic findings. AINR Jan/Feb 1993; 14: 237-241). (Reprints: Charles M Glasier MD, Department of Radiology, Arkansas Children's Hospital, 800 Marshall Street, Little Rock, AR 72202).

COMMENT. Meningiomas in children are rare (1 to $3 \%$ of intracranial tumors) and much less common than in adults (15\%). About $25 \%$ of meningiomas in children are associated with neurofibromatosis, especially type 2 .

\section{HEADACHE AS FIRST SYMPTOM OF CEREBRAL TUMOR}

Five children, ranging in age from 10 months to 4 years, all presenting initially with headache, with or without vomiting, and in whom the final diagnosis was intracranial tumor, are reported from Petah Tiqva, Israel. The initial neurologic examination, including the fundi, was normal in three patients with craniopharyngioma, pinealoma, and cerebellar astrocytoma. Two patients with medulloblastoma and fourth ventricle choroid plexus papilloma had abnormal neurologic findings at presentation. The authors stress the need for neuroimaging studies in children younger than 4 years of age who have headache, especially if accompanied by vomiting, even if the neurologic exam is normal. (Straussberg R, Amir J. Headaches in children younger than 7 years: are they really benign? Arch Neurol Feb 1993; 0ㅜ 130 [Letter to the Editor] ). 